Oliver Gassmann (2001)

\title{
Multicultural Teams: Increasing Creativity and Innovation by Diversity
}

The final version of this manuscript is published in Creativity and Innovation Management, 10(2): 88-95.

The final publication is available at www.onlinelibrary.wiley.com: http://onlinelibrary.wiley.com/doi/10.1111/1467-8691.00206/pdf DOI: $10.1111 / 1467-8691.00206$

http://dx.doi.org/ 10.1111/1467-8691.00206

Please note that differences between this manuscript and the final publication may exist. In case of questions, please contact the corresponding author as indicated below. 


\section{Multicultural Teams}

\section{Increasing Creativity and Innovation by Diversity}

Dr. Oliver Gassmann ${ }^{1}$

Until now internationalization of industrial $R \& D$ has been regarded as a necessary evil. However, in conjunction with project management attuned to different cultures, multicultural teams can increase the rate of creativity and innovation.

Globalization of competition, more demanding customers, increasing complexity and variety of products, together with escalating costs and greater technical risks, characterize the environment of European business organizations. In this environment the significance of innovation and R\&D increase disproportionately, as customeroriented products must be brought to market in ever shorter cycles. "Customization" of innovation processes, concentration on core competences, and internationalization of R\&D are pursued with vigor. Between 1989 and 1992 domestic spending on R\&D by Swiss companies rose by $4 \%$, whereas their R\&D spending in foreign countries increased by almost 35\%. In the USA in 1993 Swiss companies had the highest R\&D spending of non-US companies, amounting to USD 2.5 billion, which was higher than that of Germany, Great Britain, Canada or Japan. In the same year Swiss companies employed 15,000 persons in the USA, which is equivalent to $45 \%$ of the total number of private industry R\&D employees in Switzerland (Vorort 1994). In view of the extensive acquisition by Swiss companies of American pharmaceutical and chemical

1 Dr. Oliver Gassmann is head of R\&D Technology Management at Schindler Lifts Ltd., CH-6031 Ebikon, Switzerland. 
companies with intensive $R \& D$ activities a further increase in this $R \& D$ investment can be expected.

$<$ Fig. 1 here $>$

In spite of a high level of education, the number of highly qualified industrial researchers and developers in Switzerland is limited. Large countries such as the USA and Japan have several times as many R\&D employees (Fig. 2). Technology-based companies such as $A B B$, Hoffmann-La Roche, or Novartis therefore increasingly tap the resources of this foreign know-how. Traditional innovation processes in which a product is developed in the company's home country and then manufactured in lowwage countries occur less frequently. Instead, transnational projects with teams distributed around the world are becoming more significant.

$<$ Fig. 2 here $>$

\section{Low Acceptance of Technology Can Stimulate Innovation}

In highly-developed industrial countries a decline in public acceptance of certain technologies, and the low regard of society for technological achievements in general, can lead to the transfer of R\&D to other countries. Low acceptance of technology can result in restrictive legislation in relation to $\mathrm{R} \& \mathrm{D}$ activities or, indirectly, in conditions which do not stimulate innovation. The dangers of $R \& D$ as perceived by society lead to high costs within the company, whose amount varies from country to country. Genetic engineering and experiments on animals are currently at the center of public debate.

However, when discussing where to locate $R \& D$ it is often forgotten that a critical public attitude to technology can actually encourage innovation. China has the most stringent environmental regulations for foreigners, which can lead to rapid nationwide 
convergence on these standards. This encourages the development of dominant designs which become a de facto standard. Germany's strict environmental regulations are one of the reasons for its leading position in the field of environmental technology. Californian exhaust gas regulations have worldwide acceptance as the target standard for exhaust gas emission in the automobile field (Boutellier 1996).

California's strict safety and environmental regulations have turned the USA into $A B B$ 's key market for the development of transformers. The resistance to earthquakes and freedom from oil required in California caused $A B B$ to base their development of a transformer suitable for the "triadic" American, European, and Japanese markets there. A high level of technological awareness, and timely criticism of a specific technology, can prevent a subsequent cost-intensive changeover to a different technology. It is therefore only at a superficial level that a lack of technological acceptance appears to put highly-developed industrial countries at a disadvantage to emerging countries in relation to the location of $R \& D$. A low degree of acceptance of technology can also stimulate innovation.

\section{Technology Alone is no Guarantee of Project Success}

In many companies transfer of $R \& D$ activities abroad has led to duplication of development and global inefficiency. To reduce this effect R\&D locations must concentrate more on their individual core competences and cooperate more closely between locations. Each location must focus on the components or technologies for which it possesses the highest level of competence in the R\&D network. The greater division of work, in which each location no longer develops everything itself, permits concentration of resources. At the same time, however, this leads to an internationalization of innovative processes. To develop a new system several locations must pool their resources. Within a project there must be more 
interdisciplinary cooperation than there has been in the past. Process-oriented teams must be able to overcome boundaries of location and specialism. These teams form an overlaying organizational structure which encourages a company's long-term innovative capability. At the same time, however, they create conflicts with classical line organization structures. Open communication and common values (vision/mission) can reduce these conflicts.

$<$ Fig. 3 here $>$

Process structures and information technologies which extend beyond national boundaries are essential prerequisites. However, tailor-made processes and extensive use of state-of-the-art communications technologies do not lead to the desired project success if the human factor is neglected.

$<$ Fig. 4 here $>$

\section{International Personnel Transfers for Common Knowledge Base}

If it is necessary to communicate knowledge from one project location to another, and if the knowledge is of a type which cannot easily be coded ("tacit knowledge"), this can be achieved most effectively by transferring employees. Intensive job rotation from location to location is the basis for worldwide R\&D networks and international projects. It provides the best means of building up a common knowledge base for everybody involved in a project. Sharing of partially redundant, overlapping knowledge between team members encourages efficient communication and coordination: "Sharing redundant information promotes the sharing of tacit knowledge, because individuals can sense what others are trying to articulate" (Nonaka, Takeuchi 1995).

$<$ Fig. 4 here $>$ 
Within creative processes transfer of knowledge is ensured if employees make project-related moves between research, development, and production. Expatriates are employees delegated by headquarters to a foreign location for the purpose of diffusing corporate knowledge. At Philips value is placed on job rotation that includes both a change of function and a change of location, as this stimulates individual learning and the transfer of knowledge. The average length of stay at the Philips Research Laboratory is between five and seven years. Following this, most researchers transfer to a product development function. At Schering there is also relatively high fluctuation not related to projects between the central research locations in Richmond (USA) and Berlin.

Visiting researchers are $R \& D$ employees from a foreign location who are sent to the research headquarters to gain central research knowledge. At the giant Japanese chemical company Kao, for example, an 18 month development project for hair treatment cosmetics was carried out. Whereas projects of this nature were formerly always carried out in the company's home country, they now meet the demands of foreign markets for development activities to be carried out locally, as hair, and hair care, vary from country to country! The pre-development, conceptualization phase still takes place at the research center in Tokyo, but product development activities (implementation) are carried out at the hair cosmetics competence center in Darmstadt (Germany). Reciprocal transfer of employees ensures continuity of personnel, and complete transfer of knowledge, when the project is handed over from research to development (Fig. 6).

$<$ Fig. 6 here $>$

Technology agents from development areas are frequently sent to production locations to support the transfer of technology. At Nestlé transfer of technology from 
the R\&D locations to production locations takes place within the legally independent technology company Nestec. This company owns the patents and trademarks. Knowhow transfer is handled by means of long-term technical assistance contracts. This multilateral learning is of central significance in international R\&D projects (Fig. 7). Development of international project leaders becomes a major priority.

$<$ Fig. 7 here $>$

Companies such as $A B B, I B M$ and $A T \& T$ use staff transfers systematically as a means of developing employees' intercultural competence. There is an increasing requirement for "global managers". These trends in the internationalization of R\&D processes present new challenges to human resources management. The activities of finding, administering, and developing $R \& D$ personnel are no longer restricted to a single location but have to be coordinated worldwide.

\section{Project Leader Careers Must be Given Greater Emphasis}

Well-qualified project leaders often insist on moving into a line management function as this carries higher status. This is in contrast to the ever-increasing need for project orientation. The consequences are inefficient allocation of employees, and frustration for the individuals concerned. In view of this, one of the most important aspects of personnel development in $\mathrm{R} \& \mathrm{D}$ is to facilitate special project leader careers parallel to classical line management career paths. Financial incentives, formal increase in the status of project leaders, and guidance towards appropriate career springboards for the individual, are appropriate methods. Bosch, the automobile component supplier, has a motivating dual-career structure which enables successful project leaders to achieve promotion systematically by leading increasingly significant projects. Employees begin by leading small projects for component development with a very limited 
budget. If they do this successfully they are given responsibility for strategic projects with a greater degree of complexity and an international context.

Systematic pursuit of personnel development strategies of this nature within international $R \& D$ management can result in the creation of a permanent function dedicated to project management. For example, Hoffmann-La Roche has set up an International Project Management department in the pharmaceutical area, to which approximately 50 project leaders around the world are assigned, thereby creating a pool of personnel resources for all global $R \& D$ projects. The department is of great strategic significance for future innovation in the pharmaceutical area. The project leaders report to this geographically decentralized department and at the end of a project they are reassigned to it. The department manager has authority to delegate employees from his department to projects, and to enforce compliance with certain quality standards and project procedures. As the newly established department reports directly to top management, the status of project leaders in R\&D is significantly enhanced. The department manager is also represented on the international steering committee which decides on initiation and termination of R\&D projects and allocates budgets. By representing the interests of project leaders in that committee the department manager acts as an intermediary between the project leader and top-level decision makers.

\section{Cultural Diversity as Opportunity}

The internationalization of innovation processes demands an ever higher degree of social competence from project leaders. Misunderstandings resulting from language barriers and sociocultural differences are everyday occurrences and dominate apparently factual discussions. Cultural diversity can, however, also open up opportunities. Certain types of ability are correlated to particular cultures: British 
inventiveness, for example, or American and Japanese pragmatism. According to the head of R\&D at Hitachi Europe the underlying consideration in the internationalization of $\mathrm{R} \& \mathrm{D}$ is the conviction that mixing western and Japanese mentalities achieves high quality R\&D results faster.

However, cultural diversity alone is no guarantee of faster innovation. For innovation to be stimulated, culturally sensitive management is also required. "The approach to diversity and not the diversity itself determines the actual positive and negative outcomes" (Lane, Di Stefano 1992). A first step is recognition of the culturally dependent differences which, however, are not restricted only to regional cultures (Fig. 8).

$<$ Fig. 8 here $>$

Of all the various cultural dimensions the context relating to the stimuli accompanying communication is the most significant. In high-context cultures, of which the Japanese and Chinese cultures are examples, the meaning of a message depends heavily on the accompanying stimuli, and implicit knowledge plays a significant part. By contrast, the Scandinavian and German - and especially the Swiss-German cultures are low-context cultures in which explicit knowledge and verbal information define the message. An increasing distance between the contextual intensity of the cultures of the people involved in a project implies greater cultural diversity, which correspondingly increases the challenges confronting the project leader.

Individuals from high-context cultures have extensive informal information networks and a tendency towards close personal relationships. By contrast, low-context cultures tend to allow only a minimum of informational interference. Language is used more precisely and succinctly, which makes it easier to use information technology tools such as e-mail and fax. 
Practical problems can also arise due to different attitudes to time. The Japanese, for example, have a long planning phase and a short implementation phase, whereas for Americans the exact opposite is the case. At $M T U$, the German manufacturer of aeroengines, this led to numerous misunderstandings when working with the American partner company Pratt \& Whitney. Whereas at $M T U$ the first reaction when a problem occurred was to carry out a careful problem analysis, their American colleagues expected immediate shirt-sleeves action and a fast solution. The Europeans called this "nervous, hectic hyperactivity". At the beginning Pratt \& Whitney's roughand-ready project management methods, such as their "problem statistics", were also ridiculed at $M T U$.

\section{Management Concepts Almost Impossible to Transfer}

Japanese team management is strongly characterized by horizontal information flow structures which facilitate integrated working and team decisions. To understand the success of Japanese team management it is important to have some insight into Japanese mentality and logic. Whereas western logic is mainly Aristotelian in its nature the Japanese way of thinking is based more on a morphogenetic approach to logic which encourages heterogeneity. This enables Japanese teams to see interrelationships between experiences, and overlaps between design concepts, and to achieve conceptual cross-fertilization. It is exactly this difference in thinking that makes it difficult to apply Japanese team management to R\&D teams accustomed to thinking in the western manner.

In multicultural teams a clear sense of direction must be established at the beginning of the conceptualization phase (Fig. 9). After an initial period of euphoria over the internationalism of the project there is a drop in team morale; communication problems, and different styles of working and decision-making, lead to a culture 
shock. If the project leader does not succeed in building up trust in the early phases of the project, and holding the team together by a common vision, there is a risk that the project never gets off the ground. Especially at the beginning of international projects it is important to give priority to trust-building measures and team development. For this purpose a sociable evening out together is usually far more effective than anything that can be achieved with electronic communication.

$<$ Fig. 9 here $>$

To turn a working group that merely agrees the tasks to be done into an efficient team requires cultural assimilation. Team morale can be significantly improved if the team members learn cultural tolerance and acceptance. Seminars for intercultural learning, and training in common methods, carried out before the project starts, can be beneficial for this purpose. If the project leader is successful in stabilizing team morale at a high level, the cultural diversity can lead to totally unexpected impulses of creativity and innovation.

Building up mutual trust and respect is of central importance. Trust is especially significant in development projects, where uncertain information and wild ideas have to be brought in at an early stage. It is essential for the internationally operating team to be protected from in-company conflicts between locations, such as regional budget maximization or individual countries' autonomy. This can only be achieved by faceto-face meetings, which means that, despite all the available information technology, managers of international R\&D projects will continue to spend a large amount of their time traveling. From the team management point-of-view information technology can do no more than extend the "half-life of trust". 


\section{Bibliography}

Gassmann, O.: Internationales F\&E-Management, Oldenbourg Munich, Vienna, 1997.

Hofstede, G.: Cultures and Organizations - Intercultural Cooperation and Its Importance for Survival, London, 1994.

Lane, H.W., Di Stefano, J.J.: International Management Behaviour: From Policy to Practice, Boston, 1992.

Nonaka, I., Takeuchi, H.: The Knowledge-Creating Company. How Japanese Companies Create the Dynamics of Innovation, New York, 1995.

O'Hara-Devereaux, M., Johansen, R.: Globalwork. Bridging Distance, Culture, and Time, San Francisco, 1994.

Vorort: Forschung und Entwicklung in der schweizerischen Privatwirtschaft 1992, Schweizerischer Handels- und Industrie-Verein (Publishers), Zurich, 1994. 


\section{Illustrations}

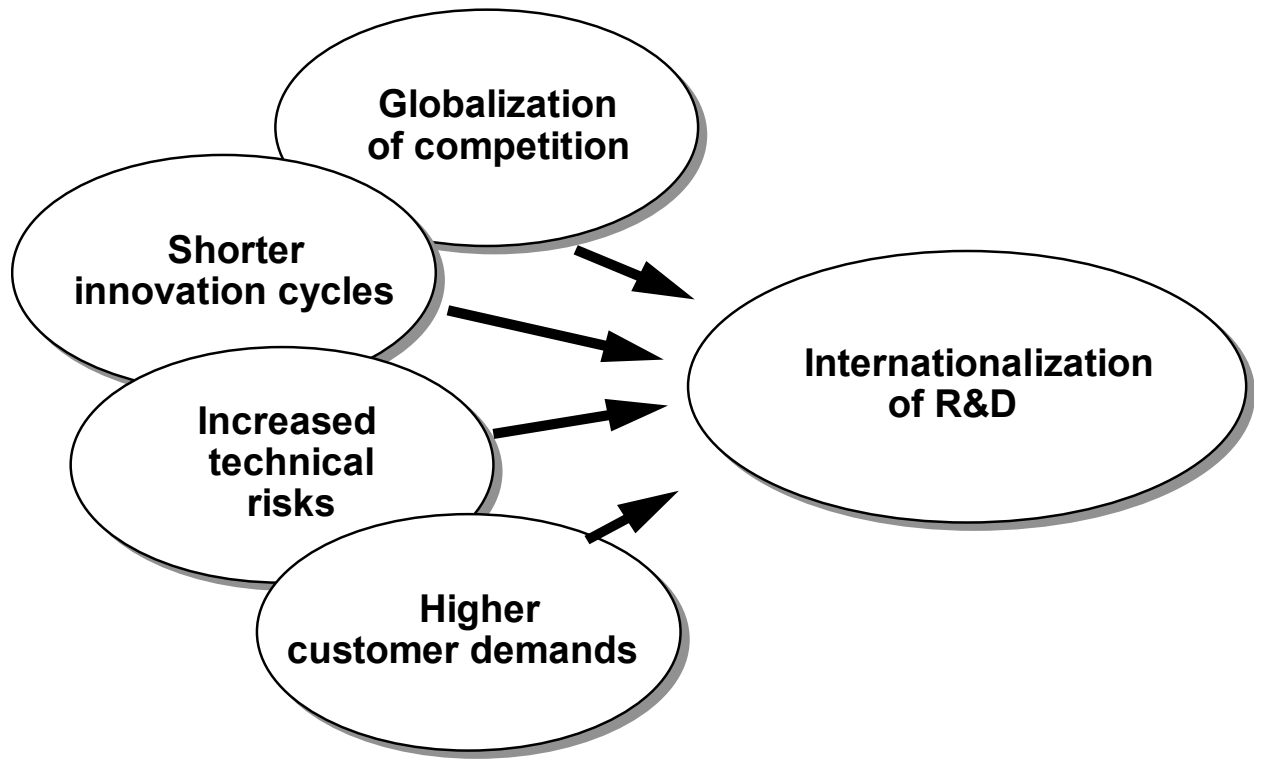

Fig. 1: Environmental change frequently forces internationalization of innovation processes. 
R\&D Employees 1990

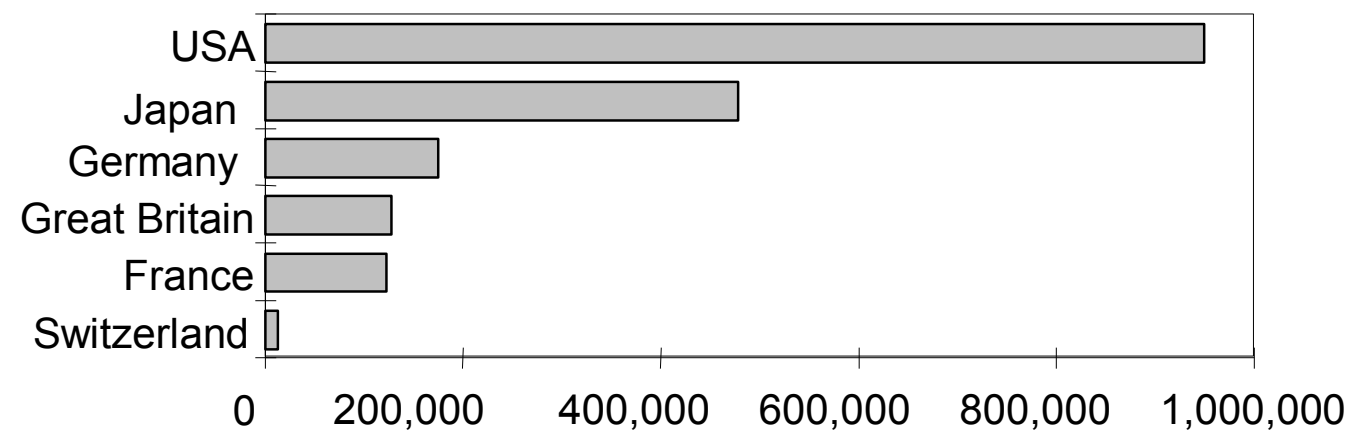

Source: $\quad$ OECD (1992).

Fig. 2: $\quad$ R\&D employees in selected OECD countries. 


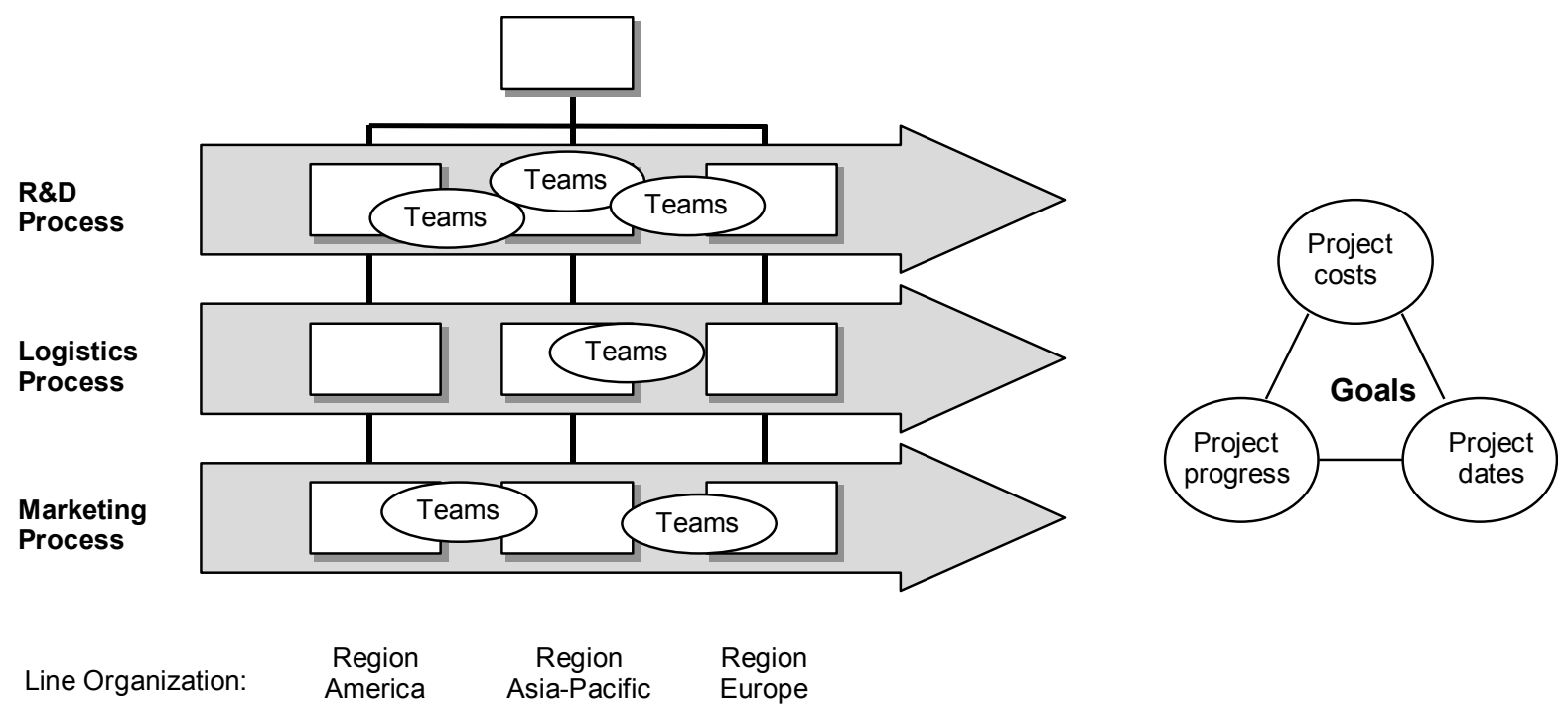

Fig. 3: $\quad$ Process-oriented team structure overlaying a classical line structure improves goal achievement. 


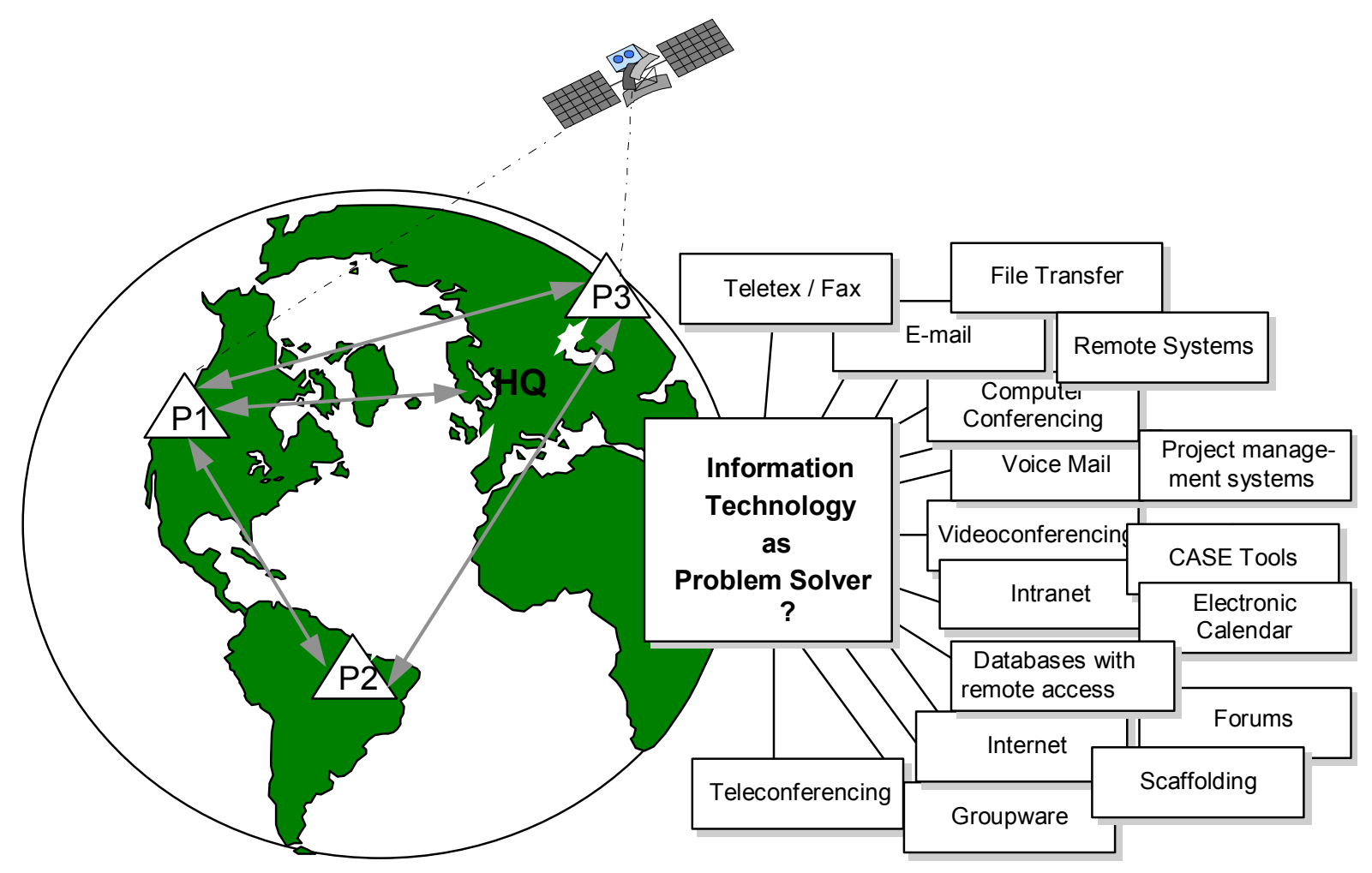

Fig. 4: Use of information technology is essential but not sufficient to ensure success. 


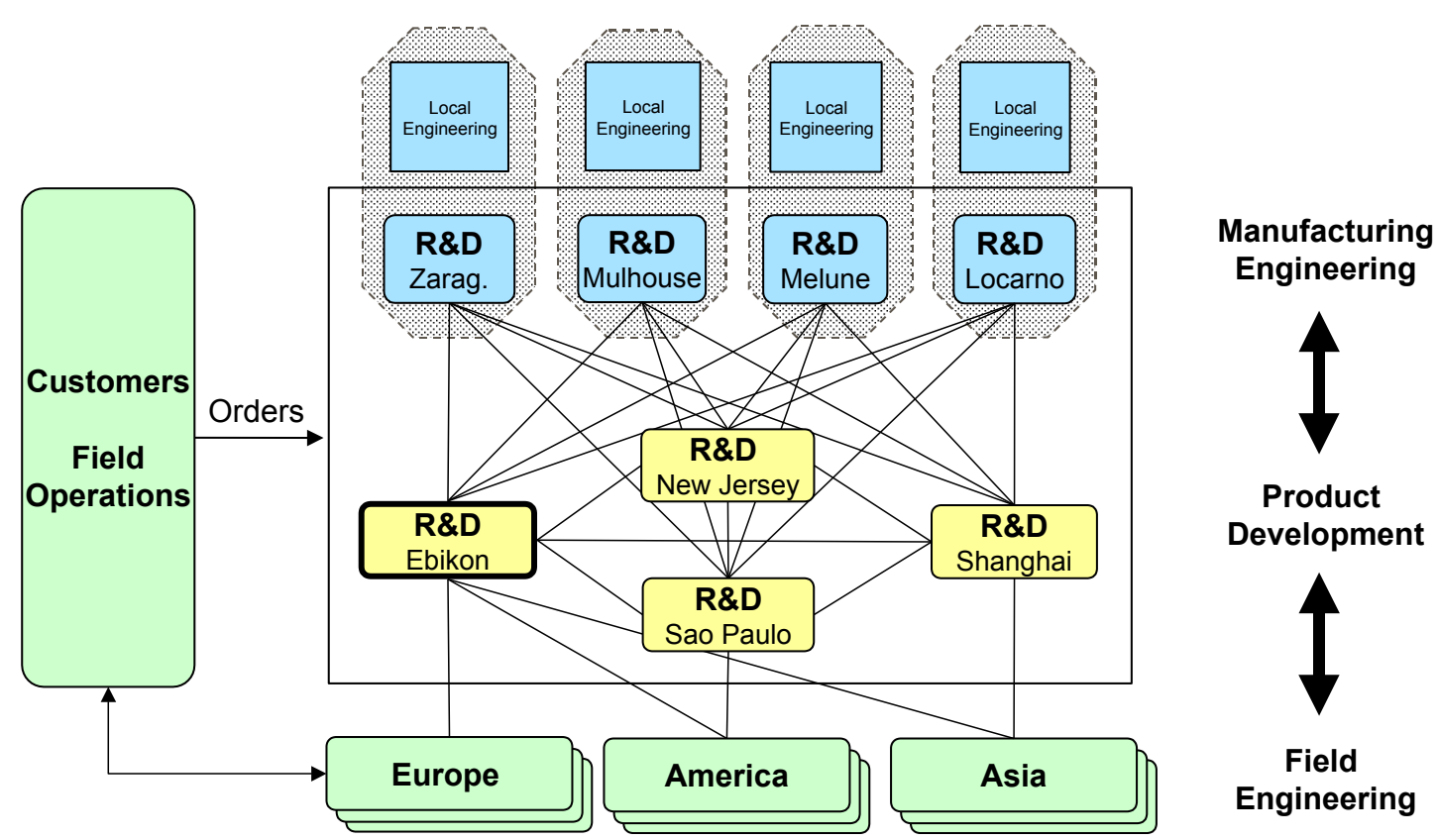

Fig. 5: $\quad$ Schindler's Competence based $R \& D$ Network requires intensive cross-border cooperation and transnational knowledge creation processes. 


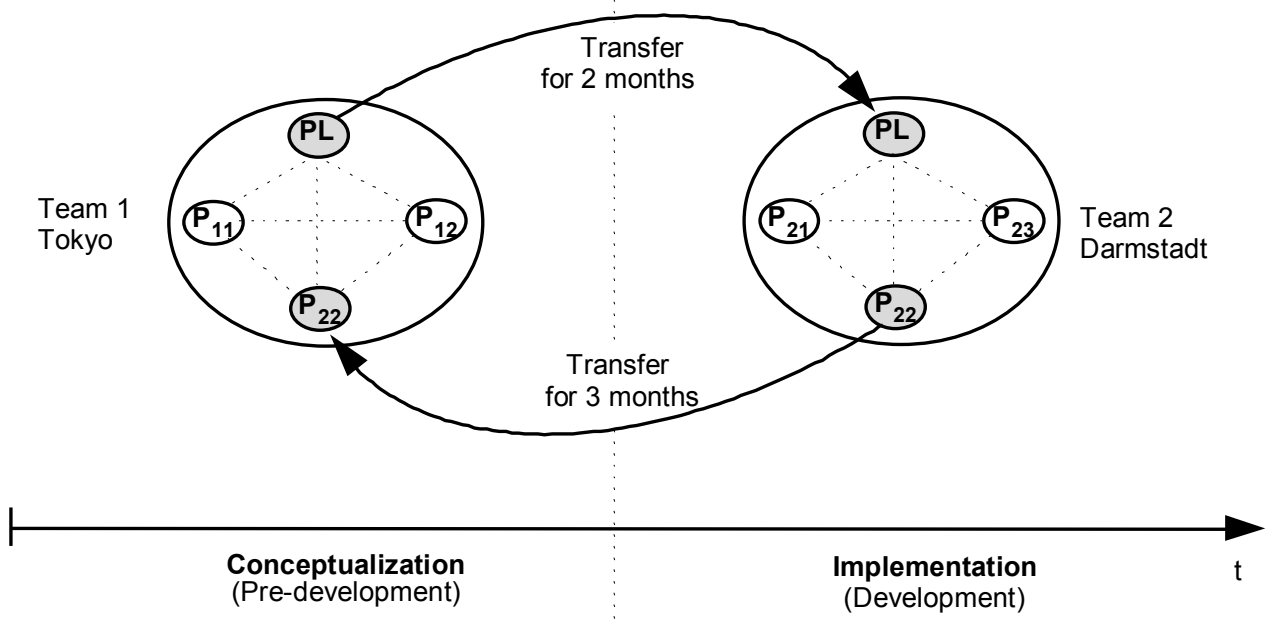

Fig. 6: $\quad$ Employee transfer safeguards knowledge. 


\section{Expatriates}

- Improve individual social competence ("cultural experience").

- Diffusion of HQ knowledge (especially in "technology-intensive" companies such as Bosch.

- Knowledge transfer with handover of project from research to development.

\section{Technology Agent}

- Support when handing over to production; knowledge transfer throughout project from development to production.

- Introduction of new technologies, support with scaling up, technology transfer.

Multilateral Learning

Build Up Redundant Resources

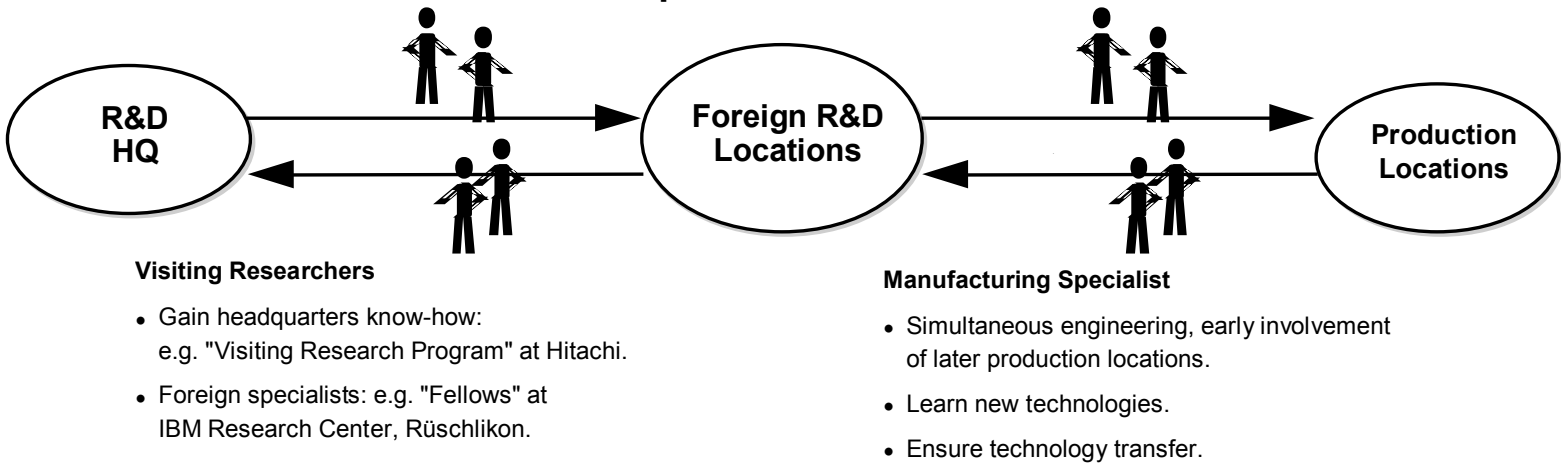

Fig. 7: $\quad$ Multilateral learning increases the long-term rate of innovation. 


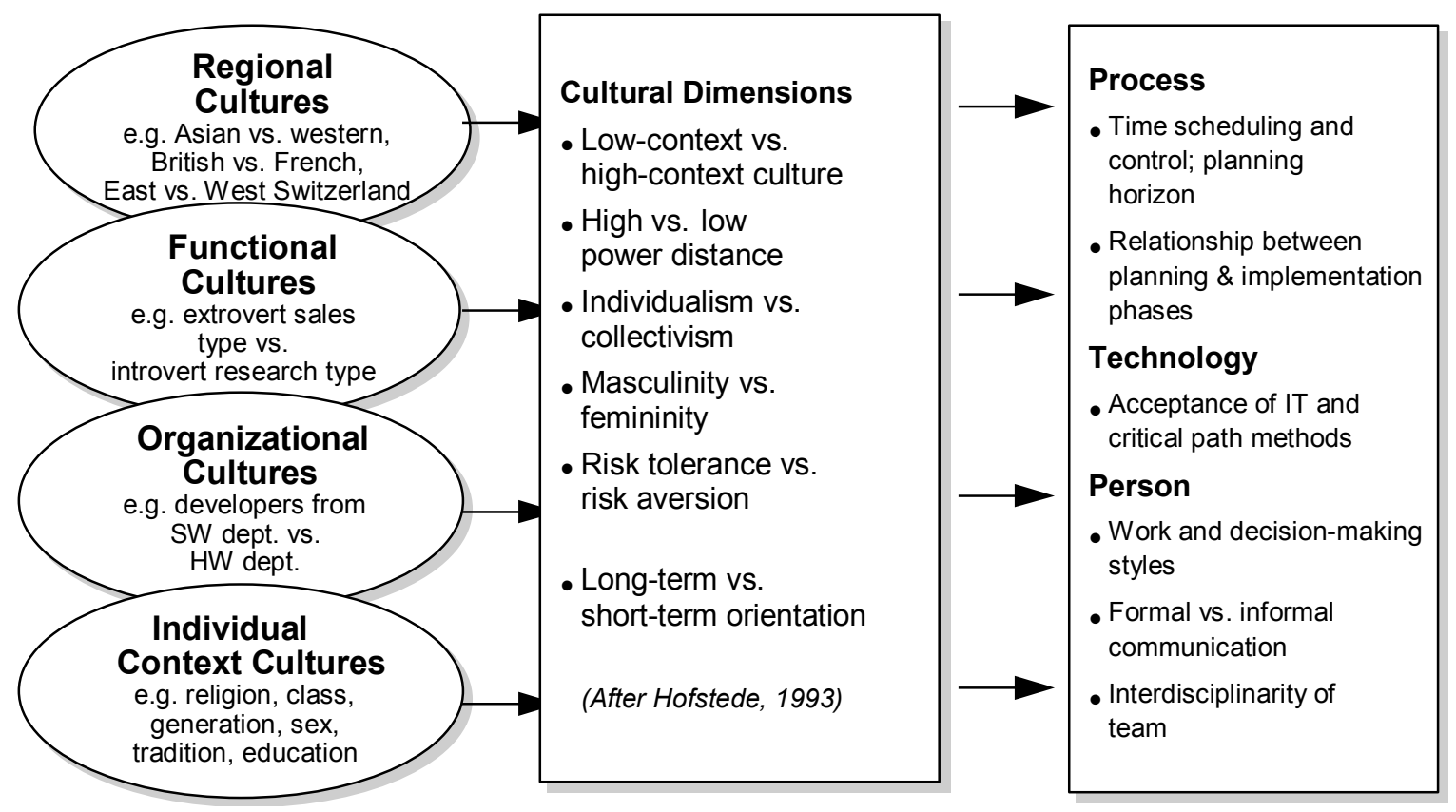

Fig. 8: $\quad$ Process, technology, and person must be matched to the team culture. 


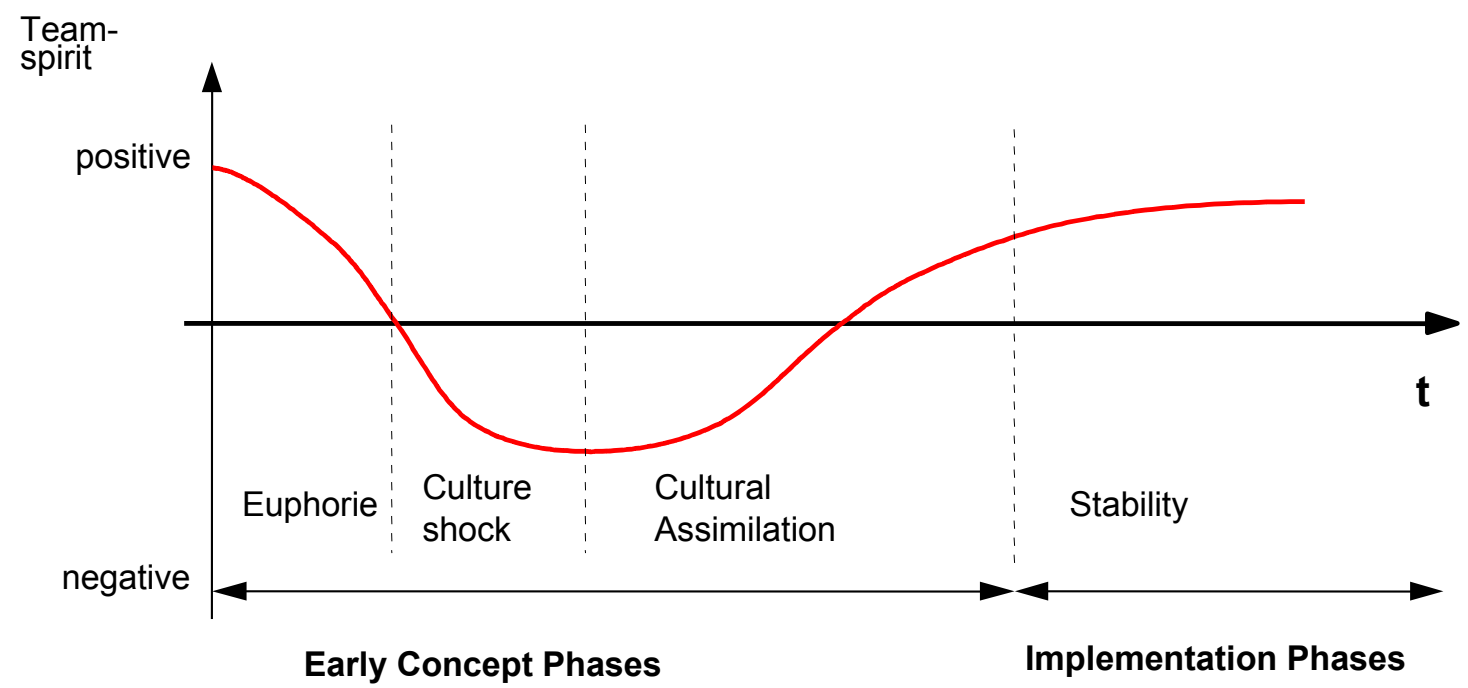

Fig. 9: $\quad$ The project leader must manage the culture shock effectively at an early stage. 